\title{
Capsule Commentary on Fredericksen et al. "Development and Content Validation of a Patient-Reported Sexual Risk Measure for Use in Primary Care"
}

\author{
Laurie C. Caines, M.D. \\ $J$ Gen Intern Med 33(10):1781 \\ DOI: $10.1007 / \mathrm{s} 11606-018-4584-6$ \\ () Society of General Internal Medicine 2018
}

University of Connecticut School of Medicine, Farmington, CT, USA.

$\mathrm{T}$ he CDC estimates that nearly 10 million new sexually transmitted infections occur every year. ${ }^{1}$ Primary care physicians are not routinely screening patients for high-risk sexual behavior. ${ }^{2}$ Improving elicitation and delivery of patient self-reported data may improve outcomes. ${ }^{3}$ To try to accomplish this, a number of self-reported assessments have been developed, referred to as patient-reported data, measures, or outcomes (PROs). PROs assess conditions and behaviors that might otherwise be overlooked or are time-consuming for providers to assess in a brief clinical encounter. Past efforts have been disappointing - perhaps due to a gap in time between PRO completion and provider appointments. Technology and touch screens may help facilitate this better. Crane et al. showed a small but insignificant increase in documentation of sexual risk behavior when providers were given same day results of PROs. This study did show improved provider awareness of other domains including depression, poor medication adherence, and substance abuse, but not necessarily on actions of providers. ${ }^{3}$ A review of computer-assisted selfinterviews (CASI) by Fairley et al. showed consistency between countries in a number of the key core sexual health questions either recommended by key organizations or routinely asked in sexually transmitted infection (STI) clinics. Studies of CASI compared with in-person interviews have shown that CASI identifies higher risk behavior more commonly than clinician interviews. Better surveillance could be done if all practices used a standardized questionnaire. ${ }^{4}$ This puts into light the most recent article by Frederickson et al. which is a multi-centered study that aimed to develop the Sexual Risk Behavior Inventory (SRBI) which is a brief,

Published online July 27, 2018

\section{REFERENCES}

1. Reported cases of STD/s on the rise in the U.S. 2015. March 2, 2018 . Available from: http://www.cdc.gov/nchhstp/newsroom/2015/std-surveillance-report-press-release.html.

2. Wimberly YH, Hogben M, Moore-Ruffin J, Moore SE, Fry-Johnson Y. Sexual history-taking among primary care physicians. J Natl Medi Assoc. 2006;98(12): 1924-9.

3. Crane HM, Crane PK, Tufano JT, Ralston JD, Wilson IB, Brown TD, et al. HIV Provider Documentation and Actions Following Patient Reports of At-risk Behaviors and Conditions When Identified by a Web-Based Point-of-Care Assessment. AIDS Behav. 2017;21(11):3111-21.

4. Fairley CK, Sze JK, Vodstrcil LA, Chen MY. Computer-assisted self interviewing in sexual health clinics. Sex Transm Dis. 2010;37(11):665-8.

5. Fredericksen RJ, Mayer KH, Gibbons LE, Edwards TC, Yang FM, Walcott M, Brown S, Dant L, Loo S, Gutierrez C, Paez E, Fitzsimmons E, Wu AW, Mugavero MJ, Mathews WC, Lober WB, Kitahata MM, Patrick DL, Crane PK, Crane HM. Development and content validation of a patient-reported sexual risk measure for use in primary care. $\mathrm{J}$ Gen Intern Med. https://doi.org/10.1007/s11606-018-4496-5. 